Check for updates

The BMJ

Cite this as: BMJ 2021;375:n2602 http://dx.doi.org/10.1136/bmi.n2602 Published: 25 October 2021

\section{Covid-19: UK stockpiles two unapproved antiviral drugs for treatment at home}

\section{Elisabeth Mahase}

The UK has started stockpiling two antiviral drugs as part of a plan to give people who are staying at home with covid-19 a treatment to reduce symptoms and the spread of the virus.

The government has purchased 480 ooo courses of molnupiravir (made by Merck Sharp and Dohme (MSD)) and 250 ooo courses of the combination of PF-07321332 and ritonavir (Pfizer), neither of which have been approved by the UK's regulator of medicines.

In its announcement the Department of Health and Social Care for England said that if the treatments were approved by the Medicines and Healthcare Products Regulatory Agency they will be rolled out to people most at risk of covid-19, with the aim of reducing symptom severity and "easing pressure on the NHS over winter."

The drugs were selected by the Antivirals Taskforce, which was formed in April with the aim of finding at least two effective treatments in $2021 .{ }^{1}$

Speaking at a televised press conference on 20 October, England's health and social care secretary, Sajid Javid, said, "It's a really new, fresh tool. These are the first antivirals ever that have been designed for covid. This is great news, but we cannot be complacent when covid-19 remains such a threat."

The health department said that the government and the NHS were now working on plans for a national study to evaluate the treatments and deploy them.

\section{Molnupiravir}

MSD reported earlier this month that molnupiravir reduced the risk of admission to hospital or death by around 50\% in non-hospitalised adults who had mild to moderate covid-19 and were at risk of poor outcomes. $^{2}$

The interim phase III trial results were released though a press release. This said that $7.3 \%$ of patients ( 28 of 385 ) who received molnupiravir and $14.1 \%$ of patients taking placebo (53 of 377) either were admitted to hospital or had died by day 29 after randomisation. At day 29 no deaths were reported in the molnupiravir group, while eight were reported in the placebo group. Recruitment to the trial was then stopped on the advice of the independent data monitoring committee because of the positive results.

\section{PF-07321332/ritonavir}

Three phase II and III trials are currently ongoing to test the combination of the novel oral antiviral candidate PF-07321332 and ritonavir in non-hospitalised patients, at low ${ }^{3}$ or high risk, ${ }^{4}$ and in adult household contacts of an individual with symptomatic covid-19. ${ }^{5}$ Details of the PF-07321332 and ritonavir phase I trial results have not been released, with Pfizer saying only that the combination was found to be "safe and well tolerated." 6

Ritonavir had previously been trialled against covid-19 in combination with lopinavir but was found to be ineffective in terms of improving survival among patients in hospital. Data from the Recovery trial showed that, at 28 days, the death rate among patients randomly allocated to receive lopinavir-ritonavir was not significantly different from the rate in people randomly allocated to usual hospital care only. Also, there was no evidence of beneficial effects on risk of progression to mechanical ventilation or on length of hospital stay. ${ }^{7}$

\section{Previous stockpiling: Tamiflu}

The government's previous record on stockpiling of antivirals had proved controversial, particularly oseltamivir (Tamiflu), stockpiled on a large scale after the $2009 \mathrm{H} 1 \mathrm{~N} 1$ "swine" flu pandemic, despite a lack of evidence to support its use. A 2009 Cochrane investigation into the evidence for the drug found that many of the studies used to support its efficacy were unpublished. The manufacturer, Roche, refused to provide the full data from the studies unless confidentiality agreements were signed, and this led to a public campaign-much of it done through The $B M J$ (bmj.com/tamiflu)-to put pressure on companies to release the underlying clinical trial data. The campaign lasted four years and was ultimately successful.

The 2014 Cochrane review that followed found no compelling evidence to support claims that oseltamivir reduced the risk of flu complications, such as pneumonia and hospital admission, which were used to justify international stockpiling. ${ }^{8}$

Mahase E. Covid-19: UK launches antivirals taskforce to deliver home treatments by autumn. BM/2021;373:n1077.

doi: 10.1136/bmj.n1077 pmid: 33903129

2 Mahase E. Covid-19: Molnupiravir reduces risk of hospital admission or death by $50 \%$ in patients at risk, MSD reports. BMJ 2021;375:n2422. doi: 10.1136/bmj.n2422 pmid: 34607801

3 A study of PF-07321332/ritonavir in non-hospitalized low-risk adult participants with covid-19. ClinicalTrials.gov. Sep 2021. https://clinicaltrials.gov/ct2/show/NCT05011513.

4 A study of PF-07321332/ritonavir in nonhospitalized high risk adult participants with covid-19. ClinicalTrials.gov. Oct 2021. https://clinicaltrials.gov/ct2/show/NCT04960202

A post-exposure prophylaxis study of PF-07321332/ritonavir in adult household contacts of an individual with symptomatic covid-19. ClinicalTrials.gov. Oct 2021. https://clinicaltrials.gov/ct2/show/NCT05047601.

Pfizer starts global phase 2/3 EPIC-PEP study of novel covid-19 oral antiviral candidate for post-exposure prophylaxis in adults. Pfizer. Sep 2021. https://www.pfizer.com/news/press-release/press-release-detail/pfizerstarts-global-phase-23-epic-pep-study-novel-covid-19.

Griffin S. Covid-19: Lopinavir-ritonavir does not benefit hospitalised patients, UK trial finds. BMJ2020;370:m2650.

doi: 10.1136/bmj.m2650 pmid: 32611587 
8 Jefferson T, Jones MA, Doshi P, etal. Neuraminidase inhibitors for preventing and treating influenza in healthy adults and children. Cochrane Database Syst Rev2012;1:CD008965.pmid: 22258996

This article is made freely available for use in accordance with BMI's website terms and conditions for the duration of the covid-19 pandemic or until otherwise determined by BMJ. You may use, download and print the article for any lawful, non-commercial purpose (including text and data mining) provided that all copyright notices and trade marks are retained. 